\title{
Nature, Culture, Gods, and Reason: Exploring Evaluative and Normative Constraints on Right Action in a Historical and Comparative Perspective
}

\author{
Christel Fricke ${ }^{1}$
}

Published online: 14 September 2015

(C) Springer Science+Business Media Dordrecht 2015

\section{Introduction}

What is right action? And why should people engage in right action? These are eminent philosophical questions. As the oldest written sources of various cultures reveal, people have been engaged in debates about right action for a very long time. Within different cultures and at different periods of time, people have suggested different accounts of right action. The studies collected in this special issue of the Journal of Value Inquiry document this pluralism of views. But they do more than this: They reveal that there is a common concern underlying people's interest in raising questions about right action, namely the interest in making sense of their lives in general and of the way they organize their societies in particular. And for answering these questions, that is, for specifying standards of right action and for providing them with motivational authority, people have, across cultural and temporal boundaries, relied on similar kinds of sources, the most prominent among them human nature, Gods, and reason.

Human nature is a product of evolutionary processes. The modern human took shape about 500.000 years ago. And, at least since language has emerged about 100.000 years ago, human nature has not undergone any substantial biological changes. Or rather: since then, the human genotype has not undergone any substantial changes. All further development and diversification within the human species does not negate the fact that, biologically speaking, all humans are essentially similar to each other. Across times and spaces, humans have developed different cultures. Among the causes for this cultural diversification are different

Christel Fricke

christel.fricke@csmn.uio.no

1 CSMN, University of Oslo, Oslo, Norway 
environments to which groups of people adapted successfully. But environmental challenges cannot alone explain cultural diversification; a multiplicity of contingent factors also had an impact. Cultural differences include differences between systems of social norms. Accordingly, people's standards of pro-social and anti-social behaviour vary across times and cultures.

One of the central questions in contemporary moral philosophy is whether the undeniable pluralism of cultures, systems of social norms, and ways to understand pro-social and right behaviour forces us to embrace moral relativism. According to moral relativism, every culture has its particular way of understanding morally right and wrong action; there is no way of comparing or ranking cultures according to the propriety or moral merit of their understanding of what morally right action is. Many modern Western moral philosophers, mainly inspired by Kant's account of human dignity, try to resist moral relativism. They argue that a system of social norms does not deserve to be called "moral" unless it implies a commitment to three basic moral values, namely moral universalism, individual autonomy, and moral equality. They consider these values as constitutive of morality. The value of universality implies that morality is all-inclusive, binding for all human beings, quite independently of their particular cultural identity, their ethnicity, gender, religious orientation, health, or socio-economic status. The value of individual autonomy implies that all adult and mentally healthy human beings are individual agents who are free to choose their actions and can be held morally accountable for their consequences. And the value of equality implies that all human beings have an equal moral status, a status all others have to respect. Moral values such as fairness and justice and the doctrine of human rights are informed by the basic values of universality, individual autonomy, and equality. But it remains an open question whether the endorsement of these values as constitutive of morality is more than just one culturally embedded assumption among others, the one characteristic of modern Western democratic societies. Is this assumption better justified than divergent understandings of morality as they can be found in other cultures?

Many people tend to think that the values underlying their own understanding of pro-social and moral behaviour are the right ones. And whereas these values do not necessarily include universality, individual autonomy, and equality, most of them include certain basic evaluative distinctions. The social and cultural psychologist Jonathan Haidt has conceptualized six such distinctions. According to his "Moral Foundations Theory", most systems of social norms, however different they may be in various respects, include distinctions between "liberty and oppression", "care and harm", "fairness/proportionality and cheating", "loyalty and betrayal", "authority and subversion", and between "sanctity and degradation."1 These distinctions can take various shapes, and the values underlying these distinctions are of various kinds. But what the ubiquitous presence of these distinctions across times and cultures reveals is a common concern, the concern to ask questions about right action and to request answers that are normatively justified, that do not merely consist of a description of actual social practices. After all, the actual practices are

\footnotetext{
${ }^{1}$ See Jonathan Haidt, The Righteous Mind. Why Good People are Divided by Politics and Religion (London: Penguin Books, 2012), pp. 125, 169.
} 
contingent, shaped by contingent evolutionary processes; as such, they cannot command any normative authority. No wonder that Georg Jellinek's notion of "the normative force of the factual" is commonly used with a touch of irony. Underlying the request for a normative justification of the standards of right action is a desire to limit the contingency of the social norms of a particular society or cultural group and thereby the contingency of the life form of its members.

Reducing the contingency of a system of social norms means strengthening the authority of these norms. Contingent social norms have merely actual authority. Actual authority is a weak kind of authority of a norm: it depends exclusively on the willingness of people to act in accordance with it. Social norms with merely actual authority lose their authority as soon as a sufficiently large number of people violate them. Processes of cultural evolution shape social norms, provide them with actual authority, then gradually deprive them of their authority and annihilate them, replacing them with other norms. In the course of such processes, different social roles take shape as well as the normative commitments attached to these roles. These roles and normative commitments are as contingent as the processes that bring them into existence. Furthermore, these processes evolve in time without ever reaching an end, without even aiming at any end. Thus, the contingency of social norms, of social roles and the normative commitments attached to them, is closely connected to their transiency.

How, then, could people reduce the contingent and transient nature of the social norms governing their societies? As the studies in the present volume reveal, over time and across cultural boundaries, people developed a variety of strategies for strengthening the authority of the social norms which they followed. People, most of them educated, raised the question "What is right action?" and they tried to provide well justified answers. For the purpose of justifying these answers, they claimed to speak in the name of Gods, a higher divine tribunal, or from some privileged point of view, accessible only to selected experts, not to common people. From this point of view, the experts had access to superior moral insights and - this should not remain unmentioned - they acquired justified authority and therefore the competence to guide and govern others, or so they claimed. Such a higher tribunal typically was that of a transcendent legislator and divine judge. And a privileged point of view could be one situated in ritual rather than in actual space or simply one of reason and superior knowledge of human nature.

Answers to the question "What is right action?" can recommend a more or less critical attitude to actual social norms: They can either confirm the actual social norms of a society or criticise them on moral grounds, demanding a more or less radical revision of actual social practices. In the former case, these answers strengthen the authority of the actual social norms considerably. People will then have reasons to obey them quite independently of any particular social pressure to do so. Or rather, they will have to submit to the social and moral guidance of the people who claim to provide such justifications - who claim to have access to superior knowledge about right and wrong action, be it of transcendent origin or a matter of superior insights into the requirements of human nature and reason. The respective norms would no longer be contingent and transient; they would have acquired a much stronger and stable authority than they originally had. 
However, in the latter case, the justified answers to the question "What is right action?" do not support the actual social norms, or not all of them. In such a case the actual social norms are found to be morally inadequate and in need of revision. Every justification and recommendation of the three basic moral values mentioned above, (universality, individual autonomy, and equality) inevitably implies a criticism of actual social practices. After all, there is no society the members of which live up to the high moral standards set by these values. Modern Western democracies are no exception.

Every theory of morality has to provide an answer to the question "What is right action?" But this is not the only requirement for a plausible moral theory. In her seminal essay on "Modern Moral Philosophy," Elizabeth Anscombe claimed that a plausible theory of morality and moral agency had to provide a psychologically well informed account of moral motivation. ${ }^{2}$ She rejected modern moral philosophies on this particular account. These philosophies - prominent examples are Kantian deontology and utilitarianism - understand moral motivation in terms of an obligation or a duty to submit to a general law, principle or rule which distinguishes between right and wrong. How can such laws, principles and rules acquire the authority to oblige people? According to Anscombe, all modern moral philosophies represent attempts at secularizing divine command theories of morality as they had been common in the Judaic-Christian tradition (and not only there, as one should add). From this tradition of moral thought modern moral theories inherit the account of morality in terms of general laws and principles which moral agents ought to follow. However, according to Anscombe, these theories do not provide a convincing alternative to the divine legislator as a source of overriding moral authority. Anscombe rejects both the Kantian doctrine of moral autonomy and the utilitarian doctrine of the best in terms of the greatest happiness of the greatest number, denying that they could provide any psychologically convincing explanation of moral motivation: Rationality - be it the rational agent's autonomy of pure practical reason or the rational agent's commitment to choosing whatever is best cannot alone motivate an agent. But what can be the source of moral motivation in a secular world? To answer this question, Anscombe suggests a twofold strategy: a return to Aristotelian virtue ethics supplemented by an empirical psychological inquiry into the nature of intentional action and its underlying motivation. According to Aristotle, acting morally comes naturally to people: Every human being who wants to live a flourishing life wants to be moral. But what is a flourishing life for a human being? And why is such a life inevitably a moral life? The key notion of Aristotle's answers to these questions is "eudaimonia" ("happiness" or "flourishing").

Anscombe's essay has given rise to a renaissance of interest in Aristotelian virtue ethics in general and in his notion of "eudaimonia" or a good, flourishing human life in particular. This philosophical interest is by no means merely historical or exegetical. Naturalizing social and moral constraints on human agency, that is, tracing their origin to human nature, to our natural needs and interest in living a

\footnotetext{
${ }^{2}$ Elizabeth Anscombe, "Modern Moral Philosophy," Philosophy 33 (1958), pp. 1-19, very frequently reprinted.
} 
good life, has become a popular project among moral philosophers. They try to find a natural commitment to morality in the way humans are embodied, some focussing on the human brain, some on human rationality, and others on sentiments more or less informed by rational reflection. After all, humans are the only animals the flourishing of which is supposed to depend on their acquisition of moral virtues; and what distinguishes humans from other animals is their being provided with rationality. Thus, being virtuous must depend at least in part on the exercise of rational capacities in one way or another. At the same time, many philosophers often take for granted that morality has to include the basic values of universality, individual autonomy, and equality - values that were most prominently promoted by deontologists and utilitarians, that is, by those whose moral theories Anscombe rejected as inadequate. It is because of their endorsement of these basic moral values that contemporary Western philosophers consider engagement in the project of naturalizing morality as promising. After all, it is human nature, largely determined by the human genotype that all humans have in common.

However, naturalistic moral theories which rely on strategies of naturalizing moral norms and divine command theories which attribute moral authority to a transcendent being are not mutually exclusive. Nor have theories of right action which relied on any or both these strategies always been committed to the three moral values considered as a sine qua non by modern Western moral philosophers. Neither divine command theories nor the strategy of justifying norms by grounding them in human nature are committed to an egalitarian understanding of human nature. ${ }^{3}$ Which social norms these theories ultimately recommend as justified, and which values inform these norms depends to a large extent on the underlying understanding of human nature: These theories may focus either on the similarities between humans qua members of the same biological species or on the actual differences between human individuals. The latter differences may well include cultural, religious, or socio-economic differences as they can be found in every society. 4

Indeed, as the first four of the studies collected here reveal, scholars in ancient China and ancient and medieval India have made different attempts at justifying social norms in order to strengthen their authority. They engaged in this project without committing themselves to the basic values informing the modern, Western understanding of morality. Instead, they were thoroughly committed to elitism, implying that the understanding of right action was restricted to a limited group of privileged people. These scholars did not consider the social norms underlying their culture as merely conventional, as products of contingent social developments, subject to historical change, and provided with merely actual authority. The strategies of justifying social norms on which these scholars relied turn out to be familiar to anyone acquainted with the history of European moral thought. They include attempts at identifying sources of the authority of these norms either in the

\footnotetext{
${ }^{3}$ On the notion of ethical naturalism and its different meanings see Julia Annas, The Morality of Happiness (New York and Oxford: Oxford University Press, 1993), pp. 135-141.

${ }^{4}$ On the different notions of human nature underlying projects of grounding norms of behaviour in human nature, see Louise M. Antony, "Natures and Norms," Ethics 111, No. 1 (2000), pp. 8-36.
} 
legislation of a transcendent being or in human nature. Inquiries into the normative discourses in ancient China and ancient and medieval India do not confirm Anscombe's distinction between divine command theories of morality and theories of moral virtues. We find instead the belief that moral motivation can arise from submission to a divine command and coincide with the natural interest to live a flourishing life at the same time. Furthermore, as these studies reveal, naturalizing morality, tracing its source in human nature, does not imply any commitment to the moral principles of universality, individual autonomy, or equality. The ancient Chinese and ancient and medieval Indian scholars engaged in such projects of justification were not entirely open-minded as to their possible findings. Rather, they knew what they were looking for. In many cases, they were looking for a nonconventional source of the authority of the actual social norms, of norms which confirmed the position of power and the privileges commonly attached to these positions held by members of the elites.

Seen in the context of the studies on ancient China and ancient and medieval India collected here, Aristotle's virtue ethics reveals itself as not as committed to the value of human equality as some of his followers today would like him to be. ${ }^{5}$ Indeed, the studies of Aristotelian virtue ethics in this collection do not provide a unanimous understanding of his views.

Are different understandings of morality more or less appropriate? And, if so, according to which standard of propriety? The studies collected in this volume do not provide us with an answer to this question. Whether the modern, Western understanding of morality is the right or proper one, better than any other, remains an open question. The trust in the superiority of this understanding of morality may well be a prejudice that remains to be justified - if such a justification is possible. One of the sources of this understanding lies in ancient Greek philosophical thought as it is commonly interpreted. The last two studies in this collection explore more recently developed strategies of naturalizing norms by arguing for their impartiality or for their normality.

The first eight studies in the present volume focus on a specific distinction between right and wrong behaviour as it can be found in Chinese, Indian, and Greek societies during a particular period of their existence. They reveal that the philosophical concern for normative justification of the authority of social norms beyond their actual conventional authority is as old as the distinction between right and wrong behaviour. What is much less widespread is an explicit commitment to the basic moral values promoted by Western moral thought.

Strategies of naturalizing norms, of claiming that their authority is grounded in human nature, were common already in ancient China. But ancient Chinese society was by no means committed to the modern, Western egalitarian understanding of morality. It was an essentially hierarchical society with limited mobility between the different levels of the social hierarchy. Naturalizing the social norms of this society was a strategy to establish and stabilize social hierarchies, of social relations of superiority and inferiority, of power relations and the privileges and responsibilities

\footnotetext{
5 Clearly, contemporary Neo-Aristotelians do not claim that the moral theory they are defending is committed to all the views Aristotle himself defended.
} 
of those at the higher end of the hierarchy. Reference to human nature did not imply any egalitarian commitment. Rather, hierarchical relations such as those between a father and his children, and in particular his sons, provided the main source of normative authority and guidance.

Christoph Harbsmeier enquires into the nature of the early Confucian classical Chinese discourse on social and moral norms. His research reveals that these norms are not typically articulated as universal prescriptions or restrictions that oblige all humans - or at least all members of the respective society - equally. Rather, they address people who have certain social roles and well defined positions within a hierarchical society and who interact with others whose positions in society are equally neatly defined. What a person is obliged to do thus depends on who he is and who the other is with whom he is dealing. The latter may be superior or inferior to the former within the hierarchies of the society. Answers to the question who a person is are not a matter of his individual autonomous choice; the strictly organized and hierarchical society accords social roles and status to its citizens. Thus, social and ethical obligations are tailor made for the interacting parties and their specific positions in society: Harbsmeier speaks of the "modality of implementation of normativity in Chinese society," and, according to him, this implementation, of ancient origin, still underlies social practices in modern China. A person's social position is determined by her or his social role - within the family or within the society at large. There are no universal principles distinguishing what is right from what is wrong for every person equally. Rather, what is right or wrong is always expressed with a double caveat: It is right (or wrong) to act in a certain way for an $\mathrm{x}$ when dealing with a $y-$ where ' $x$ ' and ' $y$ ' are placeholders for specific social roles people have. Social roles seem to be mainly determined by family relations: father and son, husband and wife, elder and younger brother. However, these roles are not as tightly connected to biological relations of kin as one might expect. Thus, the relation of the political ruler to his citizens is described in terms of a father-son relation with the corresponding obligations for both parties. Accordingly, the Confucian discourse on the ethically right and wrong is both descriptive and prescriptive: Confucius and his disciples describe a social practice which they consider appropriate for humans as they naturally are.

Michael Puett explores theories of ritual in classical China, claiming that rituals contribute to the shaping and justifying of the normative practices of the members of this society - and of societies at large. His example is that of mourning rituals. In the course of these rituals, the deceased member of the family changes status: he or she is being transformed from a family member into an ancestor. Accordingly, the attitude of the living to the deceased changes in various steps of transition from mourning into sacrificing, the proper attitude to ancestors. Puett suggests a new interpretation of the function of rituals in Classical China. Rather than reducing the function of rituals to upholding social traditions and instilling in people their social roles and corresponding predetermined obligations, Puett suggests seeing rituals as taking place in imaginary spaces, remote from the actual world, in which people can think and act in the mode of the "as if." Ritual spaces cannot be integrated into actual space. Entering into ritual space means a break from the norms that govern people's patterned responses in the actual world. This break allows for critical 
assessment of these patterned responses of belief, desire, and behaviour, for the imagination of alternative responses and for them to be practised in the ritual space - thereby paving the way for changes of behaviour in the actual world. In seeing rituals as the "ever altering means to achieve norms," Puett assimilates ritual practice with the practice of imaginary changes of standpoints. We engage in such practices for the purpose of empathizing with others or for critically assessing our beliefs and behaviour and exploring ways to improve them. Or, to put it in Puett's own words, rituals "become the means through which we train ourselves to become more able to care for those around us."

The following two studies explore normative discourses in ancient and medieval India. Like ancient Chinese society, ancient Indian society was by no means committed to an egalitarian understanding of right action. But rather than trying to ground the norms of right action in human nature, they relied on divine messages formulated in a sacred language. Learning this language and its grammar was a privilege only the members of an educated elite were allowed to enjoy.

Emilie Aussant provides an example of the way in which members of the Brahmanical priestly and intellectual elite in ancient India established and institutionalized their religious, political and social power and the authority to guide others by claiming to have superior linguistic competence: They codified Sanscrit as a holy language the use of which was restricted to a small group of experts; these experts were the only ones who could communicate directly with the Gods. Aussant shows how these texts declare themselves sāstric, that is, as commanding and regulating action, how these texts justify their existence or rather their indispensability, and how they reflect on their divine origin or their regulatory purpose. Whoever obeys the rules codified in these texts, linguistic and other, leads a life in conformity with the requirements of health and social and religious duties. Following these rules was a privilege of the members of the ruling class.

Hugo David explores medieval Brahmanical (Hindu) conceptions of religious and social norms. He focuses on philosophical theories explaining how human beings understand norms and appropriate these norms to modify their behaviour. The first part of his study delineates the ideological background of these discussions by examining the relationship between two traditional disciplines concerned with ritual, social and ethical norms referred to by the Sanskrit word dharma: Vedic exegesis (Mīmāṃsā) and Hindu law (Dharmaśāstra). He shows that these two traditions share a common concept of dharma, understood as a transcendent norm characterized by its grounding in Vedic injunctions. The second part of the study considers injunction as a philosophical problem within Brahmanism, and delineates two ways in which Brahmanical authors conceived of injunctions and articulated them in their theories of purposeful action: either as guidelines teaching the means for accomplishing what is desired or as commandments deserving to be obeyed as such, without the perspective of a beneficial result. Already discernable in earlier juridical literature, these two conceptions of the norm were clearly articulated in the second half of the first millennium in Mīmāmsāa, and were directly confronted in the discussion on the possibility of desire-less actions, thus giving the Indian debate on the "cause of human activities" its definitive shape. Modern readers well acquainted with Western philosophical accounts of moral motivation and their history will 
recognize many topics in this medieval Indian debate. Again, divine command theories of right action were not considered as incompatible with a more natural account of moral motivation which locates the motivation in the agent's desire to live a good and flourishing life. But, like Aussant, David confirms that all these considerations about right action, about what these actions should aim at and what their motivation should be, do not concern every human being, not even all members of the Indian society of that time. Rather, they address only the members of the ruling class of Brahmanians and thus affirm their elitist position.

The next four studies take us to classical Athens, thus to a culture the normative discourse of which inspires contemporary attempts at grounding moral norms in human nature to a large extent.

Paul Woodruff draws attention to a distinction between different kinds of virtues that underlies Plato's well known criticism of the poets: the distinction between perfect and imperfect duties. Perfect duties, such as wisdom, justice, and courage are exemplified by the Gods, and Plato recommends that humans take the Gods as their ethical role models. Imperfect virtues such as reverence, compassion, and good judgment are virtues for humans. These virtues represent ethical behaviour as requested from agents who are mortal, vulnerable, and ignorant. Tragic characters reveal imperfect virtues. But the poets paint an ambiguous picture of the Gods. They show them as Plato would have them, as bearers of perfect virtues, and as committed to justice in particular. But they also show them as driven by passion and the desire of revenge. Gods with such weaknesses cannot provide ethical role models. But how could Gods, immortal and omniscient as they are, provide ethical role models for humans in the first place? Since humans are essentially imperfect, their ethical commitment cannot imply a commitment to leave their imperfect nature behind. Being virtuous does not presuppose not being human. Underlying the controversy between Plato and the poets are two different and mutually incompatible normative systems: one of a moral ideal and the other of a moral practice in which humans can engage successfully.

Following Elizabeth Anscombe, Julia Annas distinguishes between two different ethical traditions: on the one hand the tradition of eudaimonism (a particular kind of virtue theory that she traces back to Aristotle) and on the other hand a tradition that attributes a central role to categorical moral duties that the moral agent has to fulfil independently of her or his desires, preferences, and goals. These traditions are first and foremost distinguished by their respective understanding of the demands which present themselves to the moral agent. In the framework of an ethical theory relying on categorical moral duties, these demands present themselves as obligations the authority of which arises from sources external to the agent. Eudaimonism, however, appeals to the agent's goal of living well, of living a flourishing life, and thus as something that acquires its authority from the agent's natural desires, preferences, and goals informed by practical reasoning about what it is right to do. Eudaimonist ethics is culturally embedded. But can it provide an agent with ethical guidance? Can it provide answers to the question what is the right thing to do under given circumstances? Julia Annas answers this question in the positive. Right actions are those a virtuous person would perform. Other than "right" and "good", 
virtue-concepts such as "courageous", "honest", "benevolent", "generous", and "compassionate", are thick ethical concepts and can thus provide ethical guidance.

Øyvind Rabbås provides a new reading of Aristotle's ethics that underlines commonalities with Kantian ideas rather than strengthening the difference between virtue theory and deontology. He does not deny that Aristotle's ethics is eudaimonist in the sense explained by Julia Annas in her contribution to this volume and elsewhere. But according to his reading, explaining what right action is takes an even more prominent place in Aristotle's moral thought than Julia Annas would have it. Rather than explaining right action in terms of the action of the virtuous agent, Aristotle first explains right action and then defines virtue in terms of right actions. But this does not mean that Aristotle relies on abstract principles and rules for explaining what is right. What reveals the proximity of his understanding of ethical demands to that of Kant, according to Rabbås, is the importance he attributes to the ethical requirement of respecting the ethical status of a person, be it a person affected by an action or the agent himself. Only an action informed by the respect due to others and to oneself can be virtuous. The respect due to a person depends on the status of this person, that is, on this person's honour (timê). Thus, Aristotle's ethics is an ethics of honour - but the notion of honour in question is more akin to the Kantian notion of dignity than to that most prominent in sociology and social anthropology. According to the latter, the dignity of a person depends mostly on her or his merits and the recognition of these merits by other members of the respective society. The 'honour' of a person has normative implications. These implications derive from the social status and social role of a person, especially as a citizen of the polis, as a husband, and as a father. Rabbås makes explicit what distinguishes Aristotle's account of a person's honour from that of Kant: according to Aristotle, honour is distributed unequally among the members of a society. Still, according to his reading, there is, within the Aristotelian account of a person's honour and status, room for "recognition respect" of the person who is doing what she is supposed to do, given her status and social role. After all, such a status does not only involve privileges and entitlements, it also involves obligations of various kinds towards various people.

Douglas L. Cairns's study explores the emotions of esteem and self-esteem in classical Athenian society. He is interested in the role of timê in Athenian law, focussing on the small corpus of Athenian forensic speeches that deal with homicide. In particular, he enquires into the relative importance of personal vengeance as requested by the families of the victims on the one hand and punishment of offenders by the state and its institutions on the other. Indeed, the state has an interest in the rule of law, and therefore in limiting self-help and controlling violence in response to homicide. So it has to gain authority over its citizens and their disposition to take punishment into their own hands. Cairn's question is to what extent the state still permits a victim's family members to pursue vengeance - be it in the name of rightful punishment of the offender or not. For answering this question, he enquires into the notion of timôria. How should we interpret and thus translate timôria as it occurs frequently in these speeches? Two interpretations seem to compete: the interpersonal interpretation as "revenge" and the legal interpretation as "justice". Cairns argues that there is "no real gulf" 
between pursuing timôria for the victim, who seeks revenge, and pursuing it for the state with its interest in justice as defined by the law: after all, to violate a citizen's right to honour (including his life and freedom from harm) is to violate the laws of the state which protects its citizens' honour. This line of argument reveals the motivation that guides people when becoming citizens of a state and submitting to the rule of its laws.

The last two studies in this collection do not address discourses about the distinction between right and wrong actions in specific societies at specific periods of their existence. Rather, they address values that play a prominent rule in discourses about moral justification common in the modern world, namely the notions of 'impartiality' and of 'normality'.

According to the modern Western understanding of morality, every moral judgment that rightly speaks in the name of morality has to be impartial. Maria Alejandra Carrasco explores what this requirement amounts to. Impartial moral judgments are judgments by a moral judge who is not partial. Carrasco distinguishes between two different notions of partiality, namely between partiality as a lack of "freedom from prejudice or bias" and partiality as having "a preference for, a favourable disposition towards, a particular person or thing." Whereas the former partiality is incompatible with the proper attitude of a moral judge, the latter is not. However, making this conceptual distinction explicit does not yet provide us with a proper understanding of the impartiality requested of the moral judge. This is because the personal attachments and commitments that are an essential part of a human being's social life and a source of her partiality in the second sense of the term are at the same time the sources of partialities in the first sense of the term. We neither request nor want the moral judge to be free of personal attachments and commitments to members of her family and friends: after all, such attachments and commitments are the very "raw material of ethics", as Carrasco puts it. But, at the same time, we request the moral judge to be impartial and thus free from the partialities that arise from these attachments and commitments. The requirements of the moral judge thus seem paradoxical: she should be partial and impartial at the same time. Carrasco distinguishes between two strategies for avoiding the paradox of this requirement: those of rule-based theories and those of communication-based theories of moral impartiality. The rule-based strategy conceives of the moral judge as a kind of institution, remote from social life and provided with a set of general moral rules which she is supposed to apply impartially to all people. These rules do not only define standards of right and wrong. They also determine which facts about a particular agent are morally relevant and which are not. The moral judge applying these rules impartially should be in no danger of partiality of the morally forbidden kind since all sources of her possible partiality have been excluded from what she needs to take into consideration when making her judgment. The communicationbased strategy attributes a very different role to the moral judge. According to this strategy, the moral judge remains part of her social community. In order to overcome her partiality as it arises from her social involvements, she is supposed to enter into a process of communication with the agents suspected of wrongdoing, requesting them to provide an explanation and justification of their doings that anyone can accept, not only those to whom they are personally attached. Implicit is 
a requirement of impartiality in the sense of "what every reasonable person has reason to agree with". Carrasco discusses the pros and cons of both strategies and then argues in favour of the communication-based strategy. Whereas this strategy cannot guarantee anything like ideal impartiality or ultimate certainty of the moral judgment, it is more sensitive to the "raw material of ethics" than the rule-based strategy. Thus, the communication-based strategy is a better resource for understanding what is the morally right thing to do for a particular agent under particular circumstances. It avoids the danger that rule-based theories run: the danger of rigorously applying rules, neglecting morally relevant particularities of the case, and thereby producing unfair, unjust, and immoral consequences.

Christel Fricke explores the normative implications of social normalities. Normal or Gaussean distributions are omnipresent both in the material world and in the world of culturally shaped behaviours of people living in societies. Various attempts have been made to naturalize distinctions between right and wrong action by mapping them on factual normality distributions of social behaviour within a particular society. Such normality distributions provide either a twofold or a threefold distinction, depending on whether the differences between ways of departing from the norm as defined by the actual majority of the items in the reference class are taken into account. Whereas the twofold distinction corresponds to the evaluative distinction between "right" and "wrong" behavior, the threefold distinction corresponds to an evaluative distinction between "worse than average", "average", and "better than average" behavior. However, Fricke argues that neither the twofold nor the threefold distinction can be naturalized by mapping it on a statistical normality distribution of social behaviours. A factual distribution of behaviours does not provide any reason for concluding that either the behaviour adapted by an actual majority or the behaviour adapted by one of the actual minorities is as such morally right.

The intention underlying the edition of this collection of studies is to contribute to the awareness of the pluralism of discourses across cultures and times which aim at the justification of social norms beyond their actual authority, contingency, and transiency. Certain strategies of justification turn out to be widespread across cultures and times: grounding norms of right action in divine commands or in human nature (understood either in biological terms or in terms of some humans' superior capacity for reasoning and acquiring knowledge). These strategies have been used for justifying the content and authority of social norms of various kinds and contents. It seems that none of these strategies prescribes a commitment to the moral values of universalism, individual autonomy, and equality. Thus, there is the suspicion that attempts at justifying the content and authority of norms of right action inevitably move in circles. Divine commands can provide justification for more or less egalitarian social norms, and so can appeals to human nature.

Most of the studies in this collection were first presented at a conference in Uppsala, co-hosted by The Swedish Collegium for Advanced Study, Uppsala, and the Centre for the Study of Mind in Nature, Oslo. I would like to thank The Swedish Collegium for Advanced Study and in particular its principal, Professor Björn Wittrock, for their generous hospitality. The Centre for the Study of Mind in Nature provided both funding and administrative support. Further thanks go to Runar 
Mæland and Sivert Ellingsen for helping with the editorial work. Finally, I would like to thank all authors for their contributions, and, last but not least, the Journal of Value Inquiry and its principal editor, John Hacker-Wright, for having agreed to publish this collection of studies. 